\title{
Punching test for estimating tensile strength and total elongation of steel sheets
}

\author{
Naotaka Nakamura ${ }^{1} \cdot$ Ken-ichiro Mori $^{1} \cdot$ Hiroki Okada ${ }^{1} \cdot$ Yohei Abe $^{1}$ \\ Received: 15 October 2020 / Accepted: 10 March 2021 / Published online: 26 March 2021 \\ (C) The Author(s) 2021
}

\begin{abstract}
A punching test for simply estimating the tensile strength and total elongation of steel sheets and formed parts was proposed. The tensile strength and total elongation were estimated from the shear stress at the maximum punching load and percentage of the burnished depth at the sheared edge of the slug measured without cutting, respectively. For a variety of steel sheets with a range of the tensile strength from 360 to $1500 \mathrm{MPa}$, linear functions for the estimation were experimentally obtained. The correlation of the estimated tensile strength of the steel sheets with the measured one from the uniaxial tensile test was considerably high, and the correlation of the estimated total elongation was high. The distributions of tensile strength and total elongation for hot- and cold-stamped parts were estimated. The proposed punching test is available under not only a laboratory environment but also a factory environment.
\end{abstract}

Keywords Punching $\cdot$ Tensile strength $\cdot$ Total elongation $\cdot$ Punching load $\cdot$ Burnished surface $\cdot$ Fracture surface

\section{Introduction}

A variety of parts used in automobiles, trains, aircrafts, farm equipment, office equipment, furniture, house appliances, computers, etc. are formed from sheets such as steel, aluminium, copper, magnesium, titanium and plastic. Steel sheets have a wide range of strength from 250 to $1500 \mathrm{MPa}$, and the application of high strength steel sheets to automobile parts is remarkable because of proper strength and costs [1]. The mechanical properties such as the strength and ductility have a large effect on sheet metal forming processes and are indispensable as properties of formed parts. Bruschi et al. [2] reviewed various testing methods of the mechanical properties of sheet metals.

Although the strength of sheet metals includes the fatigue, toughness and creep, the static strength is required as the most standard mechanical properties for the sheet metals. The static strength is generally determined by the uniaxial tensile test,

Naotaka Nakamura

n_nakamura@plast.me.tut.ac.jp

1 Department of Mechanical Engineering, Toyohashi University of Technology, Toyohashi, Aichi 441-8580, Japan and Young's modulus, Poisson's ratio, yield stress, stressstrain curve, $r$-value, total elongation and reduction of area are measured. Zhao et al. [3] examined the influence of the specimen dimensions and thickness on the stress-strain curves in the uniaxial tensile test of copper sheets and foils. Fu et al. [4] exhibited that the flow stress, fracture stress and strain decrease with decreasing ratio of the specimen thickness to the grain size in the tensile test of copper foils. Ilinich et al. [5] examined the effects of the clearance and the rolling direction in trimming of a tensile specimen on the total elongation of high strength steel sheets, since the sheared edges have a rough fracture surface, rollover and burr. Although the ultrahigh strength steel sheets have the advanced strength, Gu et al. [6] indicated the remarkable reductions in strength and ductility in the tensile test of a $1500 \mathrm{MPa}$ ultra-high strength steel sheet by the hydrogen embrittlement. Liu et al. [7] examined the hydrogen embrittlement for some ultra-high strength steel sheets. Venezuela et al. [8] examined the effect of microstructure on the hydrogen embrittlement of martensitic ultra-high strength steel sheets. Takashima et al. [9] investigated the hydrogen embrittlement behaviour of an ultra-high strength dual-phase steel sheet by sustained tensile-loading testing. Mori et al. [10] showed that the drop in total elongation by the hydrogen embrittlement for blanked ultra-high strength steel sheets is considerably larger than that in tensile strength. Tewary et al. [11] examined the effect of annealing on the 
mechanical properties of a dual-phase ultra-high strength TWIP steel sheet. Although the uniaxial tensile test has the advantage of obtaining the accurate and abundant information, the preparation of specimens, testing and measurement are laborious. Further, the tensile test is generally performed under a laboratory environment, rarely under a factory environment. It is desirable in industry to develop a simple test of the mechanical properties of sheet metals.

In the uniaxial tensile test, accurate stress at large strains cannot be measured, since a stress state is triaxial due to the occurrence of necking after passing the maximum force. After the occurrence of necking, the true stress and strain cannot be calculated from the force and gauge length, respectively. To prevent necking in the tensile test, tensile deformation was replaced with local shear deformation using slitted specimens. Bao et al. [12] designed a slit shape of the tensile specimen to cause localized shear deformation. Li et al. [13] obtained the stress-strain curve of an ultra-high strength steel sheet for a comparatively large deformation from the tensile test of a slitted specimen. Shirakami et al. [14] approximately calculated stress-strain curves of 590 and $980 \mathrm{MPa}$ high strength steel sheets for a comparatively large deformation from a simple shear test.

The most common mechanical properties of sheet metals are the tensile strength and total elongation. The yield stress and tensile strength are approximately calculated from the hardness, since the hardness is the resistance to permanent indentation [15]. The hardness test is easier than the uniaxial tensile test, and a strength distribution can be obtained. The tensile strength of steel sheets has a correlation with the total elongation [16]. To estimate the mechanical properties of sheet metals, a small punch test was developed, and a circular blank is bulged with a hemispherical punch [17]. Garcia et al. [18] estimated the yield stress and tensile strength using the small punch test, whereas the accuracy of the total elongation was low. Simonovski et al. [19] extended the small punch test to the measurement of curved specimens such as pipes. Altstadt et al. [20] exhibited that the force at a punch displacement of about 1.3 times of the specimen thickness is more accurate in estimating the tensile strength. Vijayanand et al. [21] predicted a stress-strain curve by means of the small punch test using a digital image correlation technique. Hähner et al. [22] determined the yield stress from the small punch test using finite element simulations for wide ranges of strength coefficients and work-hardening exponents. Although it is easy to estimate the tensile strength from the small punch test, a fracture test is necessary for the estimates of the total elongation and reduction of area representing the ductility.

In shearing processes such as punching and blanking, the sheets are separated by the initiation and progress of cracks, and these processes utilise a fracture phenomenon. Levy et al. [23] showed that the fracture surface at the sheared edge increases with increasing tensile strength. The initiation of cracks in shearing depends on the ductility. Sellamuthu et al. [24] predicted the tensile strength of different sheet metals from punching while they could not infer the ductility.

In this paper, a punching test for estimating the tensile strength and total elongation of sheet metals and formed parts was proposed. The tensile strength and total elongation of steel sheets were estimated from the maximum punching load and punched edge quality measured from the punching test, respectively. The proposed test is to simply estimate the tensile strength and total elongation under a factory environment by applying a punching process classified into sheet metal forming.

\section{Punching test for estimating tensile strength and total elongation of sheet metals}

\subsection{Estimates of tensile strength and total elongation from punching test}

In punching of sheet metals, the punching load increases with increasing punch stroke, then a maximum load appears and finally the load sharply drops due to the occurrence of cracks, as shown in Fig. 1. The punched edge is composed of the rollover, burnished surface, fracture surface and burr. The burnished surface is formed by plastic deformation during the punch indentation, and then the fracture surface is formed by the progress of cracks initiated from the punch and die corners. Since the punching loads for sheets having high and low strengths are high and low, respectively, the punching load is related to the tensile strength of the sheet. The initiation of cracks is determined by the ductility of the sheet. The burnished surface is stopped by the initiation of cracks, and then the fracture surface is formed [25]. For a high total elongation, the burnished surface is large and is small for a low total elongation [26]. Therefore, the percentage of the burnished or fracture surface along the punched edge is related

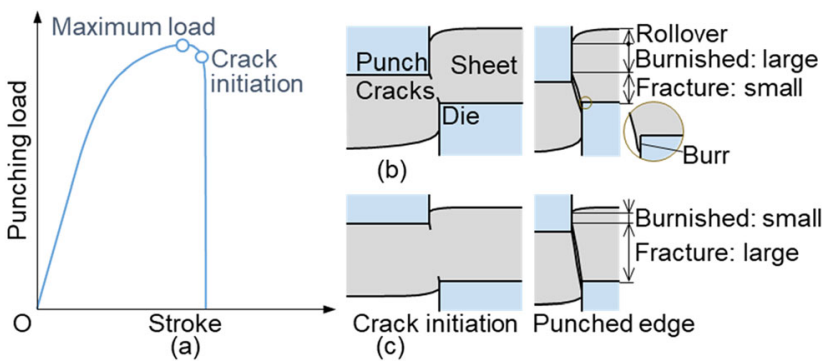

Fig. 1 Load-stroke curve and quality of sheared edge in punching of sheet metal. a Punching load-stroke curve. b High elongation. c Low elongation 
to the total elongation and reduction of area representing the ductility of the sheet.

In the present study, the tensile strength and total elongation are estimated by a punching test. The tensile strength $\sigma_{\mathrm{t}}$ of sheet metals is estimated from the maximum punching load $P_{\max }$ and is linearly approximated by

$\sigma_{\mathrm{t}}=a \frac{\sqrt{3} P_{\max }}{\pi D t}+b=\sqrt{3} a \tau_{\mathrm{p}}+b$,

where $D$ is the punch diameter, $t$ is the sheet thickness and $\tau_{\mathrm{p}}$ is the shear stress at the maximum punching load. To increase the accuracy of estimation, the coefficient $b$ is not zero, and the coefficients $a$ and $b$ are determined from a correlation between results of uniaxial tensile and punching tests.

Since the total elongation increases with increasing burnished surface and with decreasing fracture surface, the total elongation $E$ is estimated from the percentage of the burnished or fracture surface, $B$ or $F$, along the punched edge by the following linear equation:

$E=c B+d$, or $e F+f$,

where the coefficients $c, d, e$ and $f$ are determined from correlations between results of uniaxial tensile and punching tests.

\subsection{Procedures of uniaxial tensile and punching tests}

The procedures of uniaxial tensile and punching tests are given in Fig. 2. The specimen was tensile-tested, and then the middle of the undeformed grip of the ruptured specimen was punched. The width and length of the gauge section of the tensile specimen were 25 and $50 \mathrm{~mm}$, respectively. In the punching test, the maximum punching load and percentages of the burnished and fracture depths along the punched edges

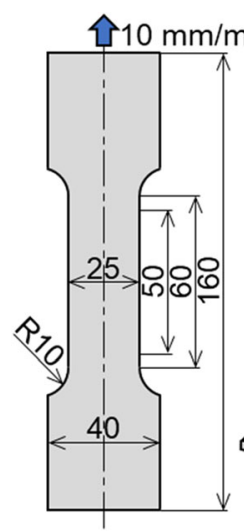

(a)

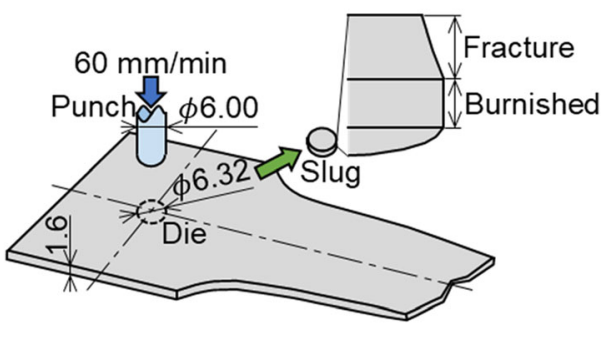

(b)
Fig. 2 Procedure of experiment for determining correlations between results of uniaxial tensile and punching tests. a Tensile test. b Punching test of undeformed grip of the slug and hole were measured. Since it is necessary to cut the inside sheared edge for the measurement of the hole, the measurement of the slug without cutting is easier. The punch and die were made of the tool steel SKD11, and the punch diameter was $6 \mathrm{~mm}$. The clearance between the punch and die was $10 \%$ of the sheet thickness, and no burr generally appears for this value [27]. The tensile and punching tests were performed three times for each sheet.

Commercial mild, 440, 590 and $980 \mathrm{MPa}$ steel sheets used for cold stamping were punched, and the thickness of these sheets was $1.6 \mathrm{~mm}$. The 440 and $590 \mathrm{MPa}$ steel sheets were high strength low-alloy steels, and the $980 \mathrm{MPa}$ steel sheet was dual phase steel.

In addition to the steel sheets used for cold stamping, a $22 \mathrm{MnB} 5$ steel sheet conventionally employed for hot stamping was heat-treated to change the tensile strength and total elongation, as shown in Fig. 3. Lee et al. [28] changed the mechanical properties of a medium carbon steel sheet by heat treatments. Although the tensile strength of the $22 \mathrm{MnB} 5$ sheet is generally heightened to about $1500 \mathrm{MPa}$ by die quenching, the strength varies with the time of natural air cooling after taking out of a furnace before die quenching. The 22MnB5 sheet is transformed into austenite by heating and is transformed into martensite, bainite and ferrite with increasing time of natural air cooling, decrease in tensile strength and increase in total elongation result. An Al-Si-coated 22MnB5 specimen was heated to $910{ }^{\circ} \mathrm{C}$ for $330 \mathrm{~s}$ in an electrical furnace. The heated specimen was put on firebricks and naturally air-cooled for 10, 30, 45 and $55 \mathrm{~s}$ including the transfer time. The cooled specimen was sandwiched between a flat cold punch and die made of the tool steel SKD61 under a contact pressure of $20 \mathrm{MPa}$ for $20 \mathrm{~s}$.

\subsection{Results of punching}

The punching load-stroke curves for the mild steel and $980 \mathrm{MPa}$ ultra-high strength steel sheets are shown in Fig. 4. The punching load for the $980 \mathrm{MPa}$ sheet is about 3 times higher than that for the mild steel sheet, whereas the stroke is shorter. The punching load for the $980 \mathrm{MPa}$ sheet sharply drops after attaining the maximum load, whereas the long peak of load appears for the mild steel sheet.

The surfaces of the sheared edges for the hole and slug of the mild and $980 \mathrm{MPa}$ steel sheets are shown in Fig. 5. In the hole and slug, the rollover, burnished surface and fracture surface are upside down. The burnished depth of the hole is larger than that of the slug, and the tendency of the fracture surface is reverse. For the mild steel sheet having high ductility, the burnished depth is large, whereas that for the $980 \mathrm{MPa}$ steel sheet having low ductility is small. The percentage of the burnished or fracture depth along the punched edge is related to the ductility of the sheet. 
Fig. 3 Heat treatment operation of $22 \mathrm{MnB} 5$ specimens having various tensile strengths and total elongations

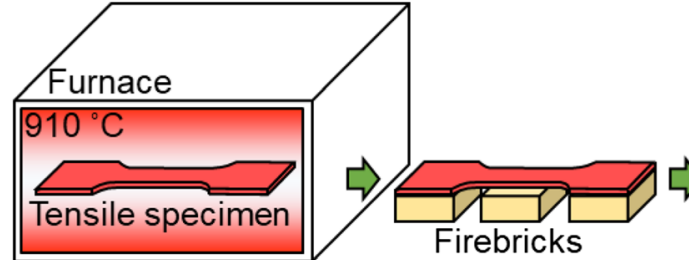

(a) Heating: $330 \mathrm{~s}$ (b) Air cooling: $10,30,45,55 \mathrm{~s}$

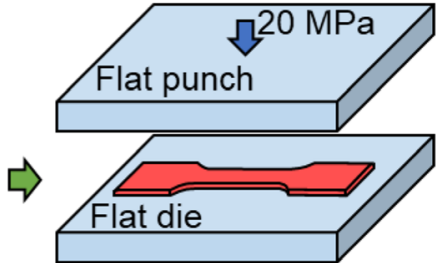

(c) Die quenching, holding time: $20 \mathrm{~s}$

\section{Estimation for steel sheets and discussion}

\subsection{Tensile strength}

The tensile strength and total elongation of the steel sheets are estimated from the punching test. For the estimation, the correlation between the tensile strength in the tensile test and shear stress at the maximum load in the punching test was obtained.

The relationship between the tensile strength and shear stress at the maximum punching load for the various steel sheets is shown in Fig. 6. The tensile strength is almost proportional to the shear stress at the maximum punching load, and the correlation coefficient between the tensile strength and shear stress at the maximum punching load is $r=0.99$ and considerably high. The coefficients $a$ and $b$ in Eq. (1) were calculated by the least squares method. The level of the estimation of the tensile strength is considerably high.

\subsection{Total elongation and reduction of area}

The relationships between the percentages of the rollover, burnished and fracture depths at the sheared edge and total elongation for the slug and hole of the various steel sheets

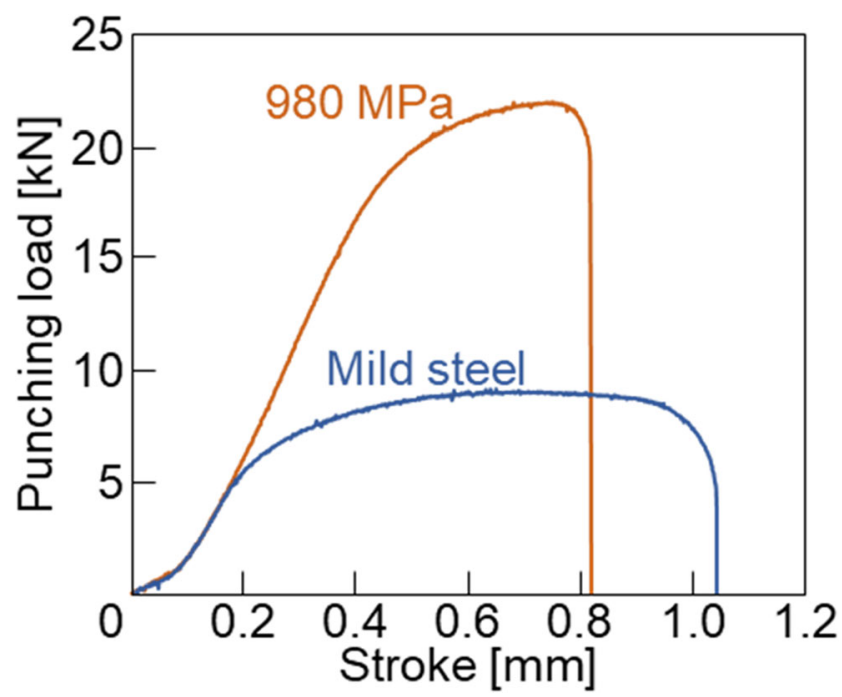

Fig. 4 Punching load-stroke curves for mild and $980 \mathrm{MPa}$ steel sheets are shown in Fig. 7. The sheared edge was composed of the rollover and burnished and fracture surfaces, and the burr was not formed for a clearance ratio of $10 \%$. The rollover depth for the slug is larger than that for the hole, and thus, the burnished depth for the slug is smaller. As the total elongation increases, the burnished depth increases, and the fracture depth decreases. This means that the burnished and fracture depths correlate with the total elongation.

The relationships between the total elongation and percentages of the burnished and fracture depths at the sheared edges of the slug and hole for the various steel sheets are shown in Figs. 8 and 9, respectively. The total elongation is almost proportional to the percentages of the burnished and fracture depths of the slug and hole. The correlation coefficients for the burnished and fracture depths for the slug are $r=0.97$ and -0.98 , respectively. On the other hand, the correlation coefficients for the burnished and fracture depths for the hole are 0.96 and -0.96 , respectively. Since the levels of the estimation of the total elongation for the burnished and fracture depths of the slug and hole are all high, the burnished depth of the slug without cutting for the measurement is appropriate.

Another parameter representing ductility of the steel sheet is the reduction of area. The relationships between the reduction of area and percentages of the burnished and fracture depths at the sheared edge of the slug for the various steel sheets are shown in Fig. 10. Although the reduction of area has almost proportional relationships with the percentages of the burnished and fracture depths, the correlation coefficients are lower than those for the total elongation.

\subsection{Effect of sheet thickness}

The accuracy of estimation for steel sheets having different thicknesses was examined by the punching test of the commercial mild, 440, 590 and $980 \mathrm{MPa}$ steel sheets used for cold stamping having thicknesses of $t=1.0$ and $2.0 \mathrm{~mm}$. In the tensile test, the conditions except for the sheet thickness were the same, and the diameter of the die used for the punching test was adjusted for a clearance ratio of $10 \%$ for a fixed diameter of the punch of $6 \mathrm{~mm}$.

The relationship between the tensile strength and shear stress at the maximum punching load for the steel sheets having different thicknesses is shown in Fig. 11. The results for $t$ 
Fig. 5 Surfaces of sheared edges for hole and slug of mild and $980 \mathrm{MPa}$ steel sheets. a Mild steel. b $980 \mathrm{MPa}$
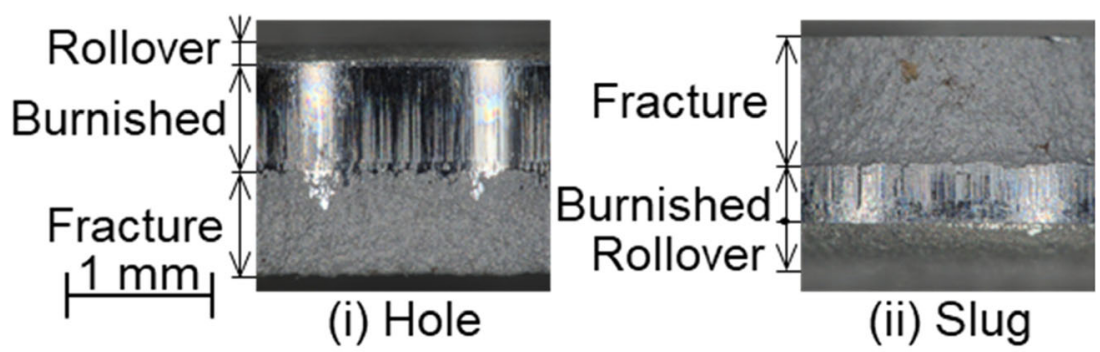

(ii) Slug

(a)

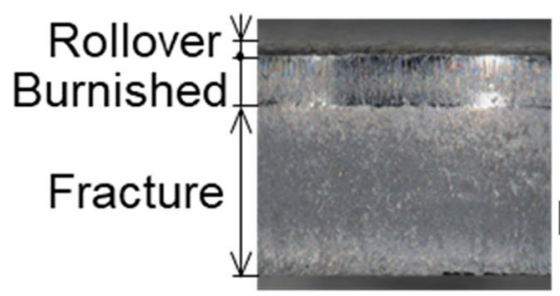

(i) Hole

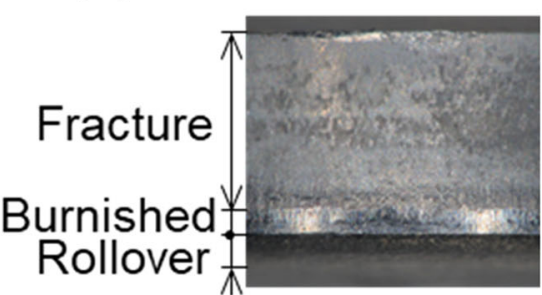

(ii) Slug

(b)

$=1.0$ and $2.0 \mathrm{~mm}$ are almost on the approximate straight line for $t=1.6 \mathrm{~mm}$ indicated in Fig. 6. It was found that the tensile strength of the steel sheet having a thickness between 1 and $2 \mathrm{~mm}$ can be estimated from the shear stress at the maximum punching load with high accuracy.

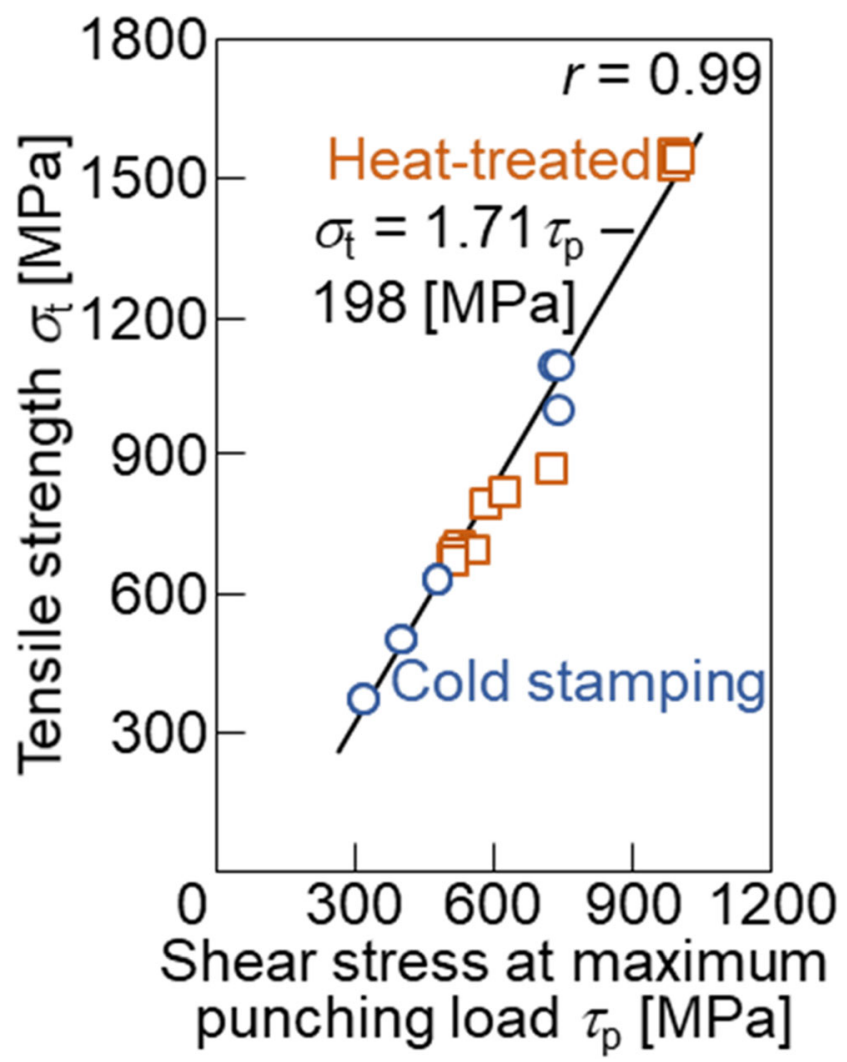

Fig. 6 Relationship between tensile strength and shear stress at maximum punching load for various steel sheets
The relationships between the total elongation and percentages of the burnished and fracture depths at the sheared edge of the slug for the steel sheets having different thicknesses are shown in Fig. 12. When the total elongations for both burnished and fracture depths are larger than $40 \%$, the linearity of the correlation is lost, and thus the total elongation cannot be modelled by one linear function for steels having considerably high ductility.

\section{Estimation for stamped parts and discussion}

\subsection{Tensile tests of full-size and miniature specimens}

To measure the distribution of the mechanical properties of stamped parts, miniature tensile specimens are conventionally cut from the part. The mechanical properties measured from the tensile test are influenced by the shape and dimensions of the specimen. To obtain similar results to the full-size tensile specimen shown in Fig. 2, the dimensions of the miniature specimen were determined to equal the ratio of the gauge length to the square root of the cross-sectional area of the parallel section, as shown in Fig. 13a [29]. The tensile strengths and total elongations of the mild and $980 \mathrm{MPa}$ steel sheets having $1.6 \mathrm{~mm}$ in thickness measured from the full-size and miniature specimens are shown in Fig. $13 \mathrm{~b}$ and $\mathrm{c}$. Although the tensile strengths for the full-size and miniature specimens are almost the same, the total elongation for the miniature specimen is slightly larger than that for the fullsize specimen.

The distributions of tensile strength and total elongation in stamped parts were estimated from the proposed punching test. The distributions were measured from punching at 
Fig. 7 Relationships between percentages of rollover, burnished and fracture depths at sheared edge and total elongation for slug and hole of various steel sheets.

a Slug. b Hole

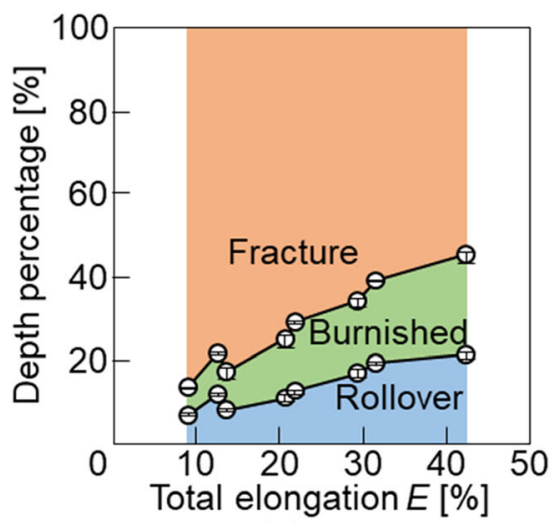

(a)

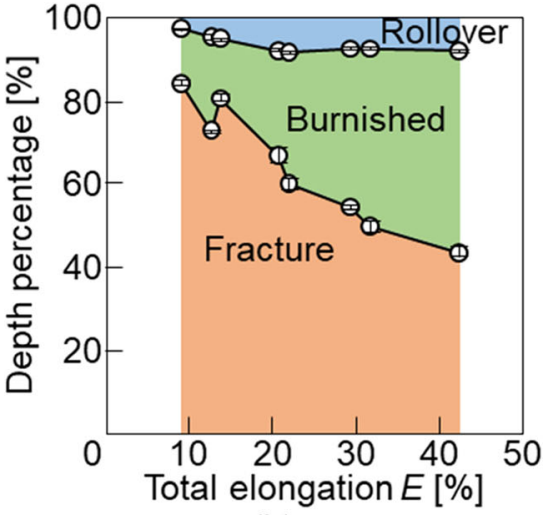

(b)
Fig. 8 Relationships between total elongation and percentages of burnished and fracture depths at sheared edge of slug for various steel sheets. a Burnished depth. b Fracture depth
Fig. 9 Relationships between total elongation and percentages of burnished and fracture depths at sheared edge of hole for various steel sheets. a Burnished depth. b Fracture depth

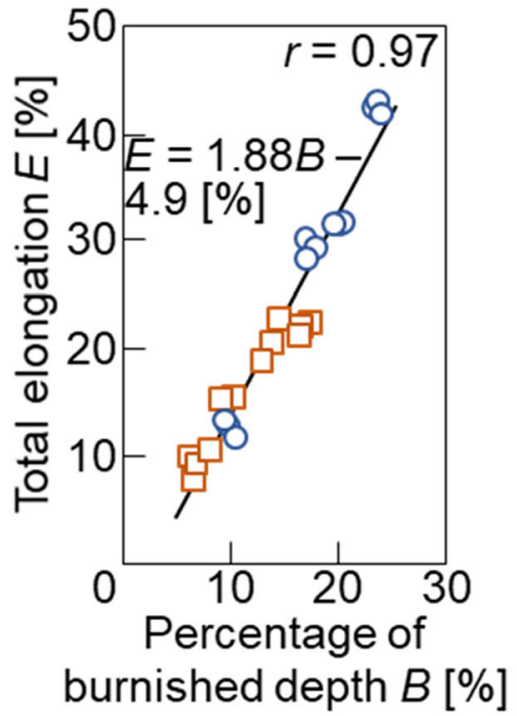

(a)

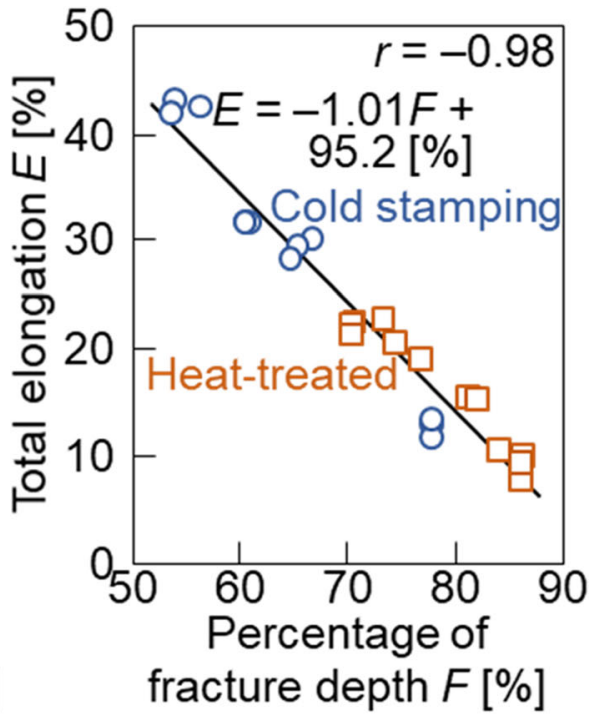

(b)

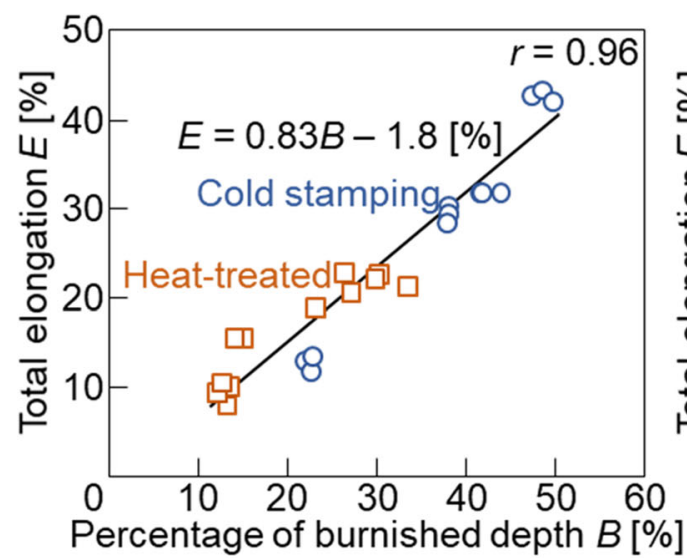

(a)

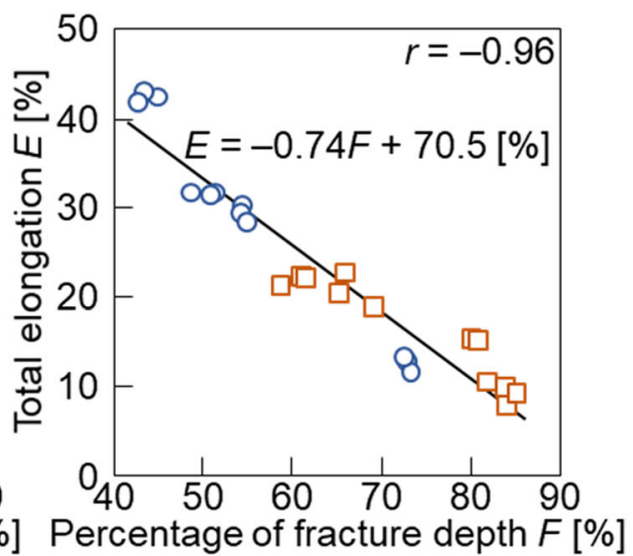

(b) 
Fig. 10 Relationships between reduction of area and percentages of burnished and fracture depths at sheared edge of slug for various steel sheets. a Burnished depth.

b Fracture depth

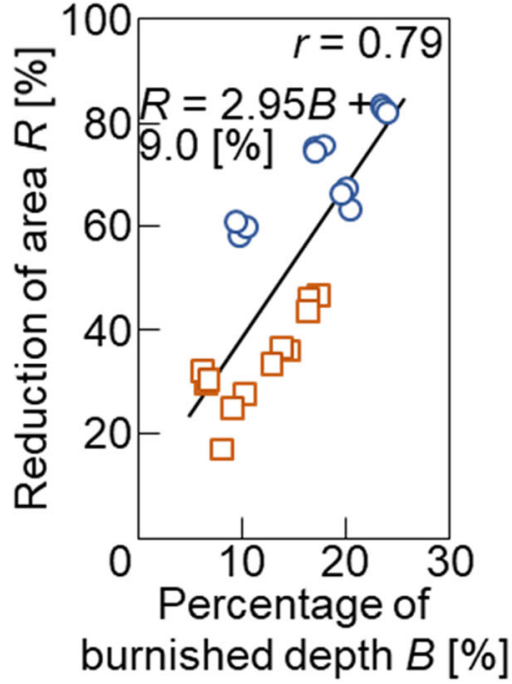

(a)

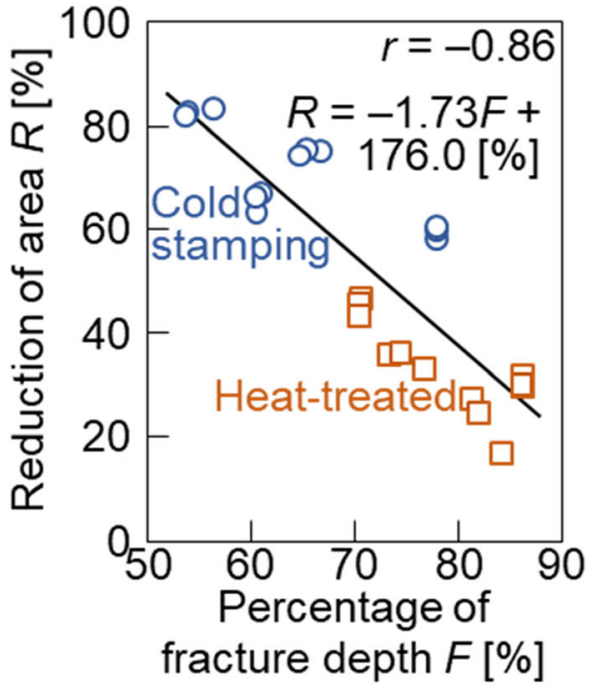

(b) intervals along a line. The tensile strength was calculated from the shear stress at the maximum punching load using the approximate straight line in Fig. 6, and the total elongation was calculated from the percentage of the burnished depth using the approximate straight line in Fig. $8 \mathrm{a}$.

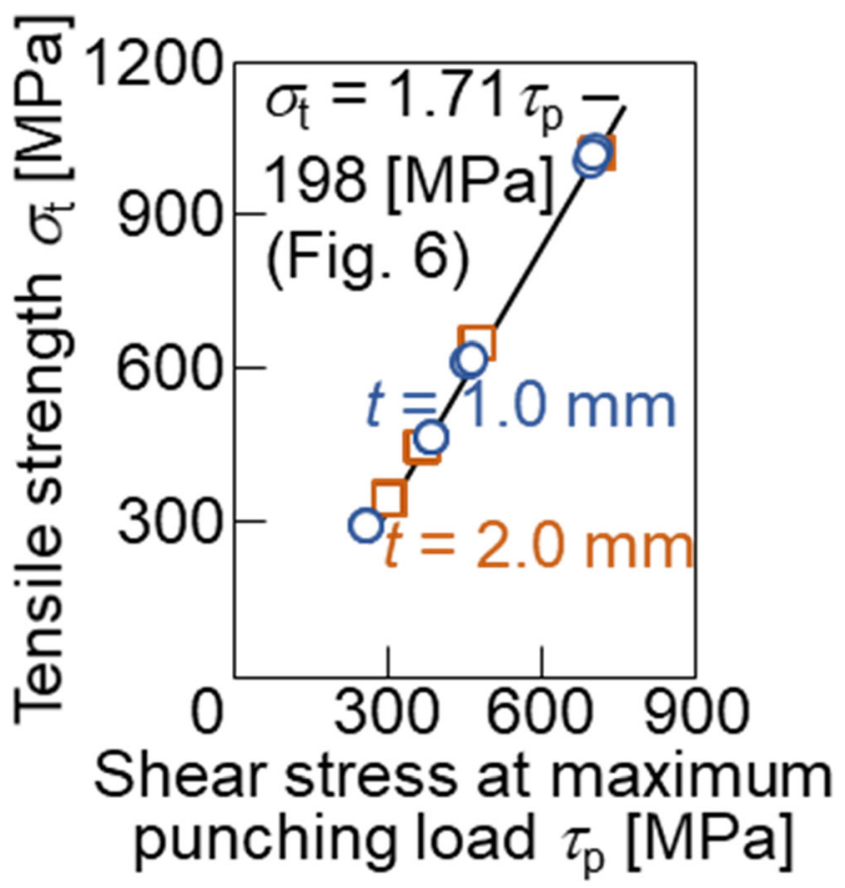

Fig. 11 Relationship between tensile strength and shear stress at maximum punching load for steel sheets having different thicknesses

\subsection{Tailored hot-stamped part}

Tailored parts having high strength and ductility zones are produced by tailored tempering in hot stamping to improve the crash safety of automobiles [30]. In tailored tempering, the high ductility zone is attained by partially preventing the martensite transformation due to the drop in cooling speed.

A tailored part was formed by a hot stamping process having tailored tempering without die heating shown in Fig. 14 [31]. In the 1st forming stage, only the high strength zone was formed with partial dies, and in the 2nd forming stage, both zones were formed with whole dies. An Al-Si-coated $22 \mathrm{MnB} 5$ blank having $1.6 \mathrm{~mm}$ in thickness was heated to $910{ }^{\circ} \mathrm{C}$ for $360 \mathrm{~s}$, and the transfer time and holding time at the bottom dead centre were 5 and $10 \mathrm{~s}$, respectively. The times of the $1 \mathrm{st}$ and $2 \mathrm{nd}$ cooling stages were 10 and $20 \mathrm{~s}$, respectively. The distributions of tensile strength and total elongation in the tailored hot-stamped part were estimated from the punching test. As a comparison, the distributions of tensile strength and total elongation were measured using the miniature tensile specimens cut by wire electrical discharge machining from the tailored part.

The distributions of tensile strength in the top of the tailored hot-stamped part obtained from the estimation and miniature specimens are shown in Fig. 15. The tensile strengths at the high strength and ductility zones are about 1500 and 700 $\mathrm{MPa}$, respectively, and the estimated tensile strength is in good agreement with the tensile strength for the miniature specimens.

The distributions of total elongation in the top of the tailored hot-stamped part obtained from the estimation and miniature specimens are shown in Fig. 16. The estimated total elongations at the high strength and ductility zones are about 
Fig. 12 Relationships between total elongation and percentages of burnished and fracture depths at sheared edge of slug for steel sheets having different thicknesses. a Burnished depth. b Fracture depth

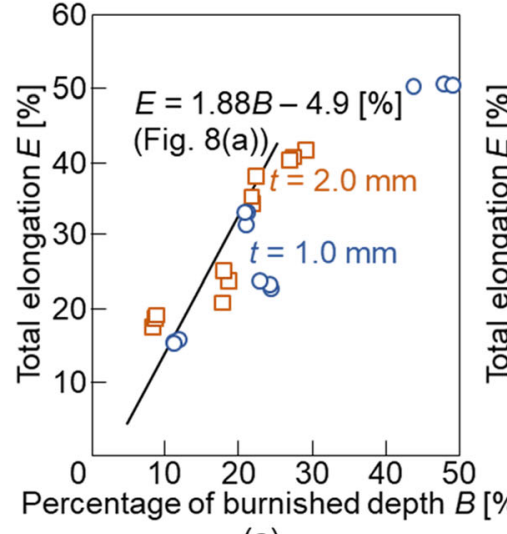

(a)

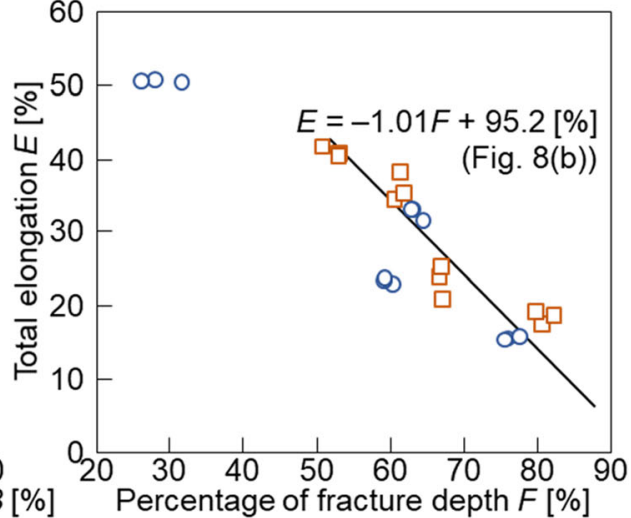

(b)
Fig. 13 Dimensions of miniature specimen and tensile strengths and total elongations of mild and $980 \mathrm{MPa}$ steel sheets having $1.6 \mathrm{~mm}$ in thickness measured from full-size and miniature specimens. a Miniature specimen. b Tensile strength. c Total elongation

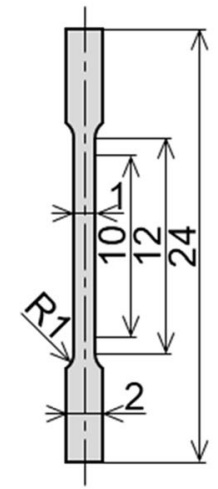

(a)

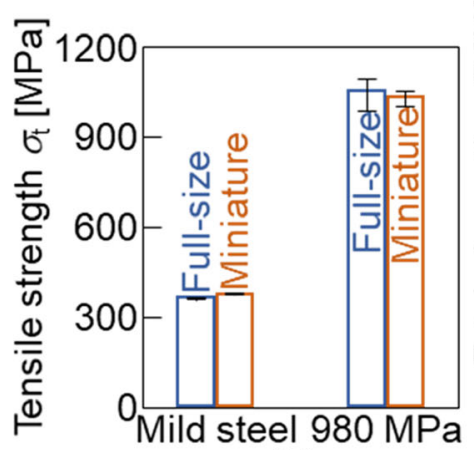

(b)

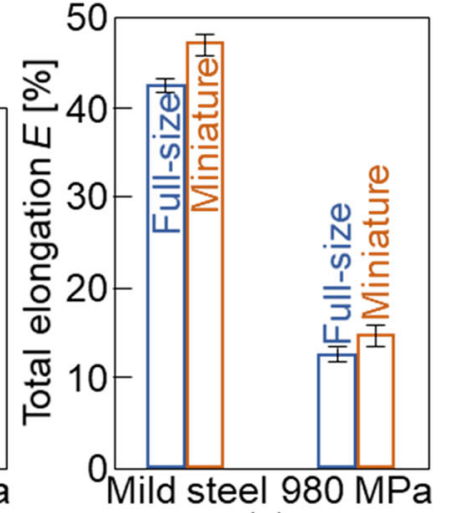

(c)
Fig. 14 Tailored tempering conditions without die heating in hot stamping

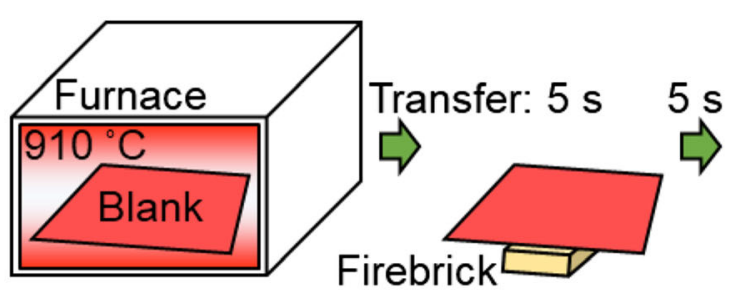

(a) Heating: $360 \mathrm{~s}$ (b) 1st cooling stage: $10 \mathrm{~s}$

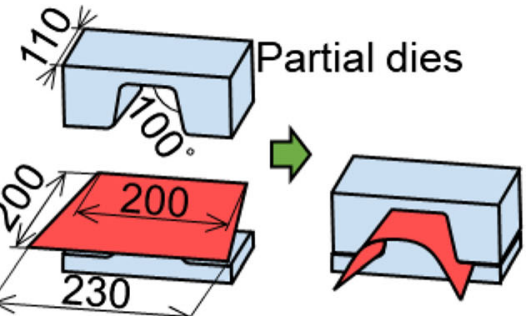

(c) 1 st forming stage, holding time: $10 \mathrm{~s}$

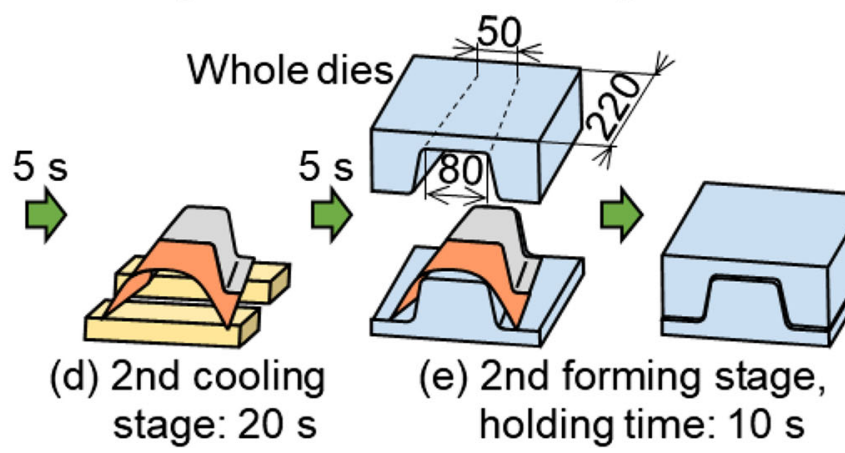




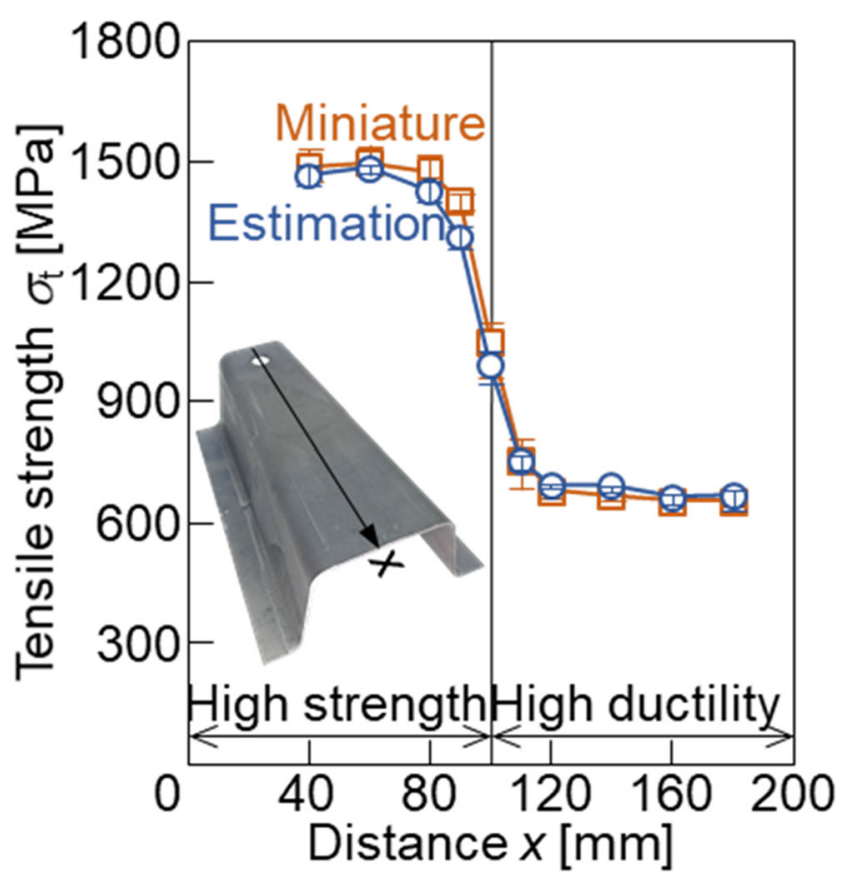

Fig. 15 Distributions of tensile strength in top of tailored hot-stamped part obtained from estimation and miniature specimens

7 and 27\%, respectively. Although the estimated elongation in the high ductility zone is in good agreement with the elongation for the miniature specimens, the estimated elongation in the high strength zone is lower than the elongation for the miniature specimens.

\subsection{Cold-stamped part}

A mild steel sheet having $1.6 \mathrm{~mm}$ in thickness was coldstamped, as shown in Fig. 17a. The tensile strength and total elongation of this sheet were $360 \mathrm{MPa}$ and $39.5 \%$, respectively. The tensile strength for the cold-stamped part is increased

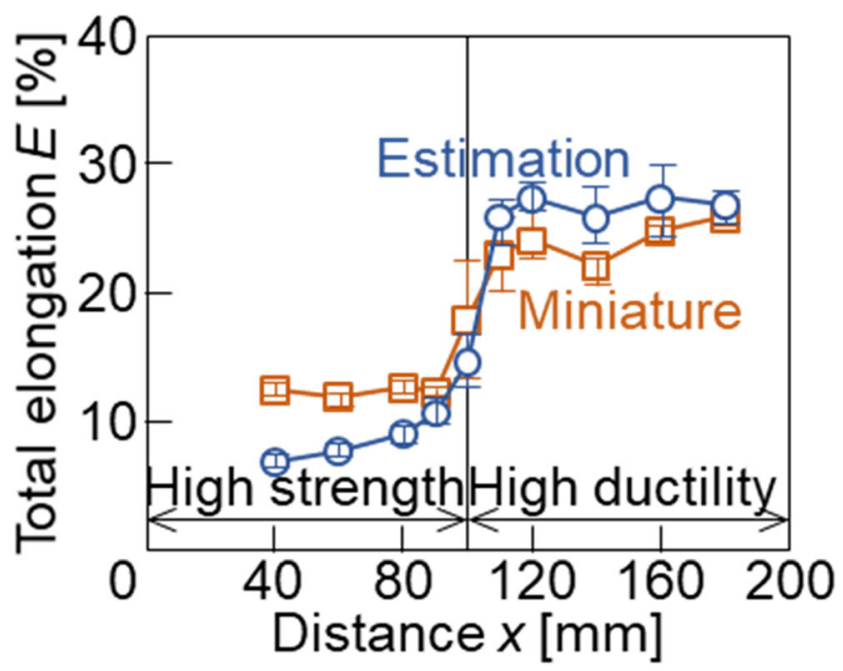

Fig. 16 Distributions of total elongation in top of tailored hot-stamped part obtained from estimation and miniature specimens by plastic deformation, and the total elongation is decreased. The tensile strength and total elongation in the top and flange of the stamped part were estimated, and the miniature specimens were cut from the 5 portions a, b, c, d and e.

The stamping process was simulated by the dynamic explicit commercial finite element code LS-DYNA, and the distribution of calculated equivalent strain is given in Fig. 17b. The sheet was modelled to be isotropic elastic-plastic because of an $r$-value of 0.97 and divided into one layer of solid elements. The sheet was automatically meshed by LS-DYNA, and the element size was about $2 \mathrm{~mm}$. Remeshing was not performed because of not large deformation. The flow stress of the sheet was measured from the uniaxial tensile test to be $\sigma$ $=570 \varepsilon^{0.16} \mathrm{MPa}$. The punch, die and blankholder were divided into rigid shell elements. The coefficient of friction between the sheet and tools was assumed to be 0.2 , since the experiment was performed without lubrication. As the equivalent strain increases, the tensile strength increases and the total elongation decreases. The equivalent strain is non-uniformly distributed in the stamped part, and thus, the tensile strength and total elongation are also distributed.

The distributions of tensile strength in the top and flange of the stamped part obtained from the estimation and miniature specimens are shown in Fig. 18. The estimated tensile strength is lower than the tensile strength for the miniature specimens. Since the top and flange of the stamped part were slightly curved, shearing in punching is incremental, and thus, the estimated tensile strength from the punching load was reduced by the effect of the shear angle [32].

The distributions of total elongation in the top and flange of the stamped part obtained from the estimation and miniature specimens are shown in Fig. 19. The estimated elongations for the portions a and c are in good agreement with the elongations for the miniature specimens, whereas the elongations for the portions $b, d$ and e for the miniature specimens are considerably lower.

In a stamped part, the thickness is non-uniformly distributed, and the cut miniature specimens have a thickness distribution. When the specimen having a thickness distribution is tensile-tested, uniform deformation is not obtained by the concentration of deformation at the thinnest portion, and thus, the total elongation becomes small. The distributions of thickness in the gauge section of the miniature specimens cut from the 5 portions are illustrated in Fig. 20. Although the thicknesses for the portions a and $\mathrm{c}$ are uniform, those for the portions $\mathrm{b}, \mathrm{d}$ and e are considerably different. The thickness in the top of the tailored hot-stamped part in Section 4.2 was uniform. The discrepancy in Fig. 19 is caused by the distribution of thickness of the miniature specimens. The proposed punching test is advantageous to the estimation of the total elongation for stamped parts having a distribution of thickness. 
Fig. 17 Cold-stamped part and distribution of calculated equivalent strain. a Stamped part. b Equivalent strain

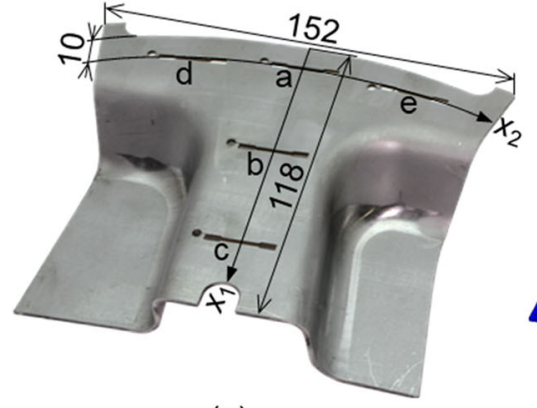

(a)

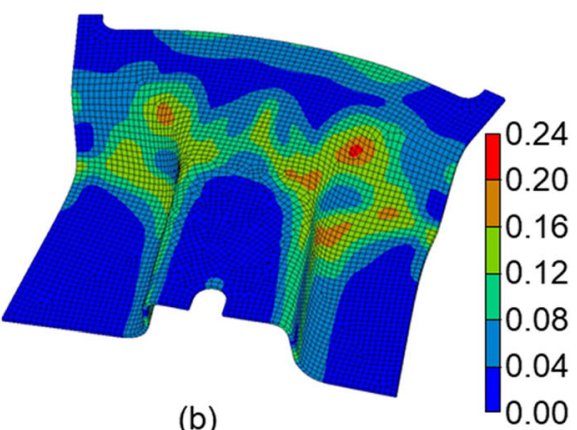

(b)
Fig. 18 Distributions of tensile strength in top and flange of stamped part obtained from estimation and miniature specimens. a Top. b Flange

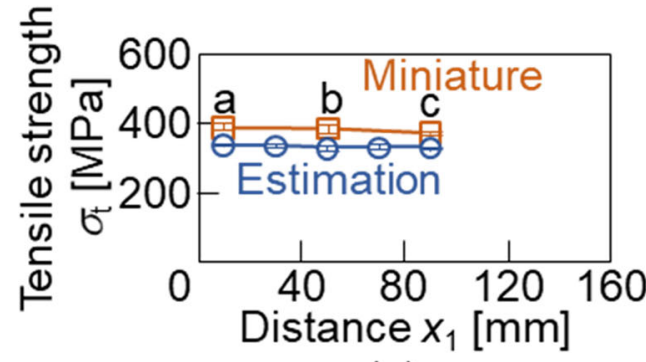

(a)

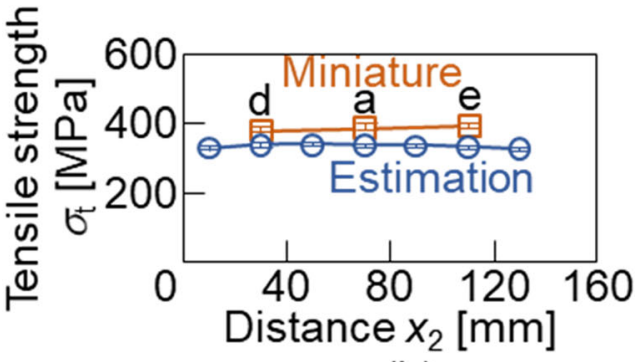

(b)

\section{Conclusions}

A punching test for simply estimating the tensile strength and total elongation of steel sheets and formed parts was developed. The results measured from the punching test were correlated with those measured from the tensile test. The tensile strength and total elongation in the tensile test were estimated from the shear stress at the maximum punching load and percentage of the burnished depth at the sheared edge of the slug, respectively. The obtained results are summarised as follows:
1) The level of estimation of the tensile strength from the shear stress at the maximum punching load was considerably high.

2) Since the levels of estimation of the total elongation for the burnished and fracture depths of the slug and hole were all high, the burnished depth of the slug without cutting was appropriate for this estimation.

3) The level of estimation of the reduction of area was lower than that of the total elongation.

4) The distributions of tensile strength and total elongation in a stamped part were measured from punching at intervals along a line.
Fig. 19 Distributions of total elongation in top and flange of stamped part obtained from estimation and miniature specimens. a Top. b Flange

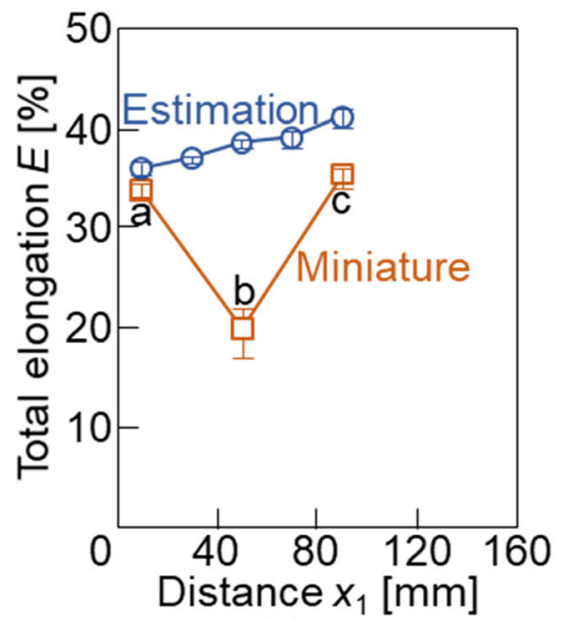

(a)

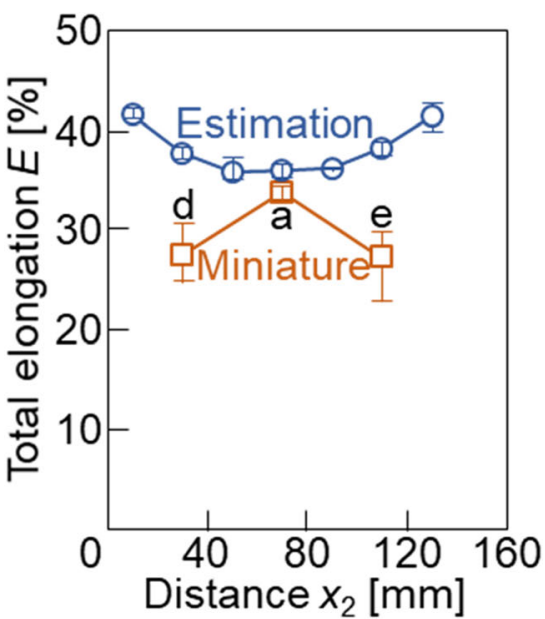

(b) 


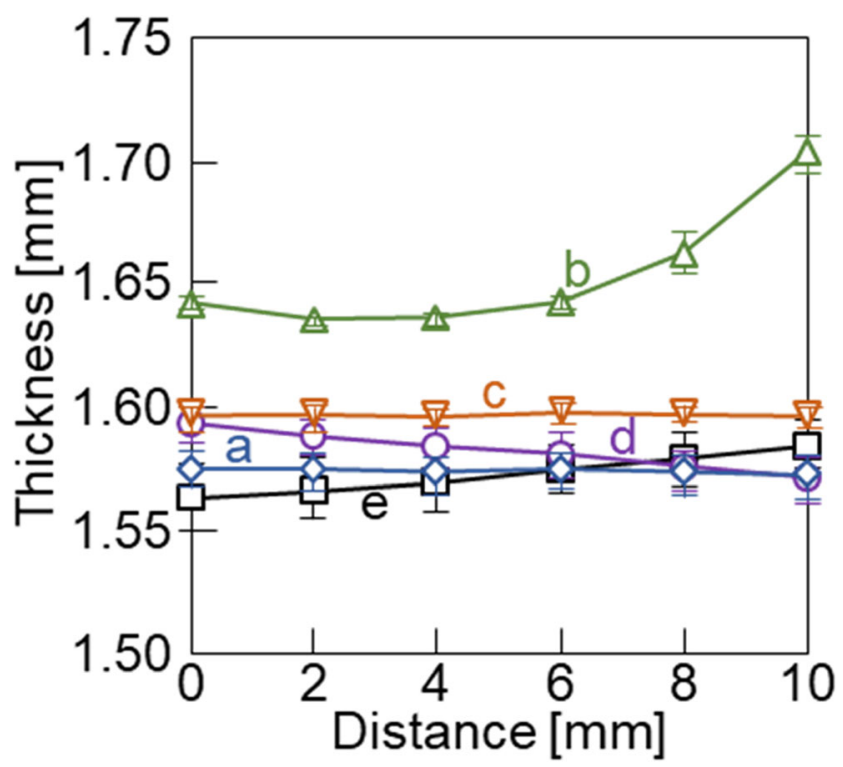

Fig. 20 Distributions of thickness in gauge section of miniature specimens cut from 5 portions

Since the mechanical properties of sheet metals vary for each production lot, it is significantly important to control the mechanical properties for stamping. Not only the mechanical properties of stamped parts but also the formability is influenced by the mechanical properties of the sheet metals. It is desirable in industry to develop a simple test for estimating the mechanical properties of sheet metals. The developed punching test is available for forming environments unlike the conventional tensile test and is applicable to ductile metals, not just steels. By punching the edge of coils before stamping, the mechanical properties of sheet metals are easily verified for massive production of sheet metal parts, and the useful information for the quality control of the stamped parts is obtained.

Since blanked sheets are conventionally stamped in sheet metal forming, the mechanical properties of sheet metals for stamping are easily controlled by extending the present test to blanking processes. The relationships between the blanking load and tensile strength and between the sheared edge quality and total elongation are similar to those for the punching test. The mechanical properties can be controlled by monitoring online the blanking load and sheared edge quality. On the other hand, repeating local punching is required to estimate the distributions of tensile strength and total elongation in a formed part. If the punching equipment is installed in a robot having a $\mathrm{C}$ frame commonly used for spot resistance welding, the punching operation becomes easy and speedy.

Funding This work was supported by JSPS KAKENHI Grant-in-Aid for Scientific Research (B) of Number JP18H01749.
Data availability The data that support the findings of this study are available from the corresponding author on reasonable request.

\section{Declarations}

Competing interest The authors declare no competing interests.

Open Access This article is licensed under a Creative Commons Attribution 4.0 International License, which permits use, sharing, adaptation, distribution and reproduction in any medium or format, as long as you give appropriate credit to the original author(s) and the source, provide a link to the Creative Commons licence, and indicate if changes were made. The images or other third party material in this article are included in the article's Creative Commons licence, unless indicated otherwise in a credit line to the material. If material is not included in the article's Creative Commons licence and your intended use is not permitted by statutory regulation or exceeds the permitted use, you will need to obtain permission directly from the copyright holder. To view a copy of this licence, visit http://creativecommons.org/licenses/by/4.0/.

\section{References}

1. Tisza M, Czinege I (2018) Comparative study of the application of steels and aluminium in lightweight production of automotive parts. Int J Lightweight Mater Manuf 1(4):229-238. https://doi.org/10. 1016/j.ijlmm.2018.09.001

2. Bruschi S, Altan T, Banabic D, Bariani PF, Brosius A, Cao J, Ghiotti A, Khraisheh M, Merklein M, Tekkaya AE (2014) Testing and modelling of material behaviour and formability in sheet metal forming. CIRP Ann Manuf Technol 63(2):727-749. https://doi.org/10.1016/j.cirp.2014.05.005

3. Zhao YH, Guo YZ, Wei Q, Topping TD, Dangelewicz AM, Zhu YT, Langdon TG, Lavernia EJ (2009) Influence of specimen dimensions and strain measurement methods on tensile stress-strain curves. Mater Sci Eng A 525(1-2):68-77. https://doi.org/10.1016/j. msea.2009.06.031

4. Fu MW, Chan WL (2011) Geometry and grain size effects on the fracture behavior of sheet metal in micro-scale plastic deformation. Mater Des 32(10):4738-4746. https://doi.org/10.1016/j.matdes. 2011.06.039

5. Ilinich AM, Golovashchenko SF, Smith LM (2011) Material anisotropy and trimming method effects on total elongation in DP500 sheet steel. J Mater Process Technol 211(3):441-449. https://doi. org/10.1016/j.jmatprotec.2010.10.014

6. Gu JL, Chang KD, Fang HS, Bai BZ (2002) Delayed fracture properties of $1500 \mathrm{MPa}$ bainite/martensite dual-phase high strength steel and its hydrogen traps. ISIJ Int 42(12):1560-1564. https://doi.org/ 10.2355/isijinternational.42.1560

7. Liu Q, Zhou Q, Venezuela J, Zhang M, Atrens A (2017) Hydrogen influence on some advanced high-strength steels. Corros Sci 125: 114-138. https://doi.org/10.1016/j.corsci.2017.06.012

8. Venezuela J, Zhou Q, Liu Q, Li H, Zhang M, Dargusch MS, Atrens A (2018) The influence of microstructure on the hydrogen embrittlement susceptibility of martensitic advanced high strength steels. Mater Today Commun 17:1-14. https://doi.org/10.1016/j. mtcomm.2018.07.011

9. Takashima K, Yoshioka Y, Yokoyama K, Funakawa Y (2018) Hydrogen embrittlement behavior of ultra-high strength dual phase steel sheet under sustained tensile-loading test. ISIJ Int 58(1):173178. https://doi.org/10.2355/isijinternational.ISIJINT-2017-315 
10. Mori K, Abe Y, Sedoguchi K (2019) Delayed fracture in cold blanking of ultra-high strength steel sheets. CIRP Ann Manuf Technol 68(1):297-300. https://doi.org/10.1016/j.cirp.2019.04.111

11. Tewary NK, Ghosh SK, Mandal A, Chakrabarti D, Chatterjee S (2020) Effect of annealing on the microstructure, texture and mechanical properties of a dual-phase ultrahigh-strength TWIP steel. Metall Mater Trans A 51:4483-4498. https://doi.org/10.1007/ s11661-020-05851-9

12. Bao Y, Wierzbicki T (2004) On fracture locus in the equivalent strain and stress triaxiality space. Int J Mech Sci 46(1):81-98. https://doi.org/10.1016/j.ijmecsci.2004.02.006

13. Li S, He J, Gu B, Zeng D, Xia ZC, Zhao Y, Lin Z (2018) Anisotropic fracture of advanced high strength steel sheets: experiment and theory. Int J Plast 103:95-118. https://doi.org/10.1016/j. ijplas.2018.01.003

14. Shirakami S, Tsunemi Y, Yoshida T, Kuwabara T (2018) Workhardening behaviour of sheet steels in large strain regions and its simple approximation. J Phys Conf Ser 1063:12107. https://doi.org/ 10.1088/1742-6596/1063/1/012107

15. Kalpakjian S, Schmid SR (2014) Manufacturing engineering and technology, 7th edn. Pearson, pp 70-71

16. Mori K (2020) Review of shearing processes of high strength steel sheets. J Manuf Mater Process 4(2):54. https://doi.org/10.3390/ jmmp4020054

17. Manahan MP, Argon AS, Harling OK (1981) The development of a miniaturized disk bend test for the determination of postirradiation mechanical properties. J Nucl Mater 104:1545-1550. https://doi. org/10.1016/0022-3115(82)90820-0

18. Garcia TE, Rodriguez C, Belzunce FJ, Suarez C (2014) Estimation of the mechanical properties of metallic materials by means of the small punch test. J Alloys Compd 582:708-717. https://doi.org/10. 1016/j.jallcom.2013.08.009

19. Simonovski I, Holmström S, Bruchhausen M (2017) Small punch tensile testing of curved specimens: finite element analysis and experiment. Int J Mech Sci 120:204-213. https://doi.org/10.1016/ j.ijmecsci.2016.11.029

20. Altstadt E, Houska M, Simonovski I, Bruchhausen M, Holmström S, Lacalle R (2018) On the estimation of ultimate tensile stress from small punch testing. Int J Mech Sci 136:85-93. https://doi.org/10. 1016/j.ijmecsci.2017.12.016

21. Vijayanand VD, Mokhtarishirazabad M, Peng J, Wang Y, Gorley M, Knowles DM, Mostafavi M (2020) A novel methodology for estimating tensile properties in a small punch test employing in-situ DIC based deflection mapping. J Nucl Mater 538:152260. https:// doi.org/10.1016/j.jnucmat.2020.152260
22. Hähner P, Soyarslan C, Çakan BG, Bargmann S (2019) Determining tensile yield stresses from small punch tests: a numerical-based scheme. Mater Des 182:107974. https://doi.org/ 10.1016/j.matdes.2019.107974

23. Levy BS, Van Tyne CJ (2012) Review of the shearing process for sheet steels and its effect on sheared-edge stretching. J Mater Eng Perform 21:1205-1213. https://doi.org/10.1007/s11665-011-9997-x

24. Sellamuthu P, Collins PK, Hodgson PD, Stanford N (2013) Correlation of tensile test properties with those predicted by the shear punch test. Mater Des 47:258-266. https://doi.org/10.1016/ j.matdes.2012.11.057

25. Hatanaka N, Yamaguchi K, Takakura N (2003) Finite element simulation of the shearing mechanism in the blanking of sheet metal. J Mater Process Technol 139(1-3):64-70. https://doi.org/10.1016/ S0924-0136(03)00183-3

26. Mori K, Abe Y, Suzui Y (2010) Improvement of stretch flangeability of ultra high strength steel sheet by smoothing of sheared edge. J Mater Process Technol 210(4):653-659. https:// doi.org/10.1016/j.jmatprotec.2009.11.014

27. Hilditch TB, Hodgson PD (2005) Development of the sheared edge in the trimming of steel and light metal sheet: part 1 - experimental observations. J Mater Process Technol 169(2):184-191. https://doi. org/10.1016/j.jmatprotec.2005.02.266

28. Lee YW, Son YI, Lee SJ (2013) Microstructure and mechanical properties of spheroidized D6AC steel. Mater Sci Eng A 585:94 99. https://doi.org/10.1016/j.msea.2013.07.040

29. Masete MS, Muchavi NS, Chikosha S (2018) The effect of specimen geometry on tensile properties of titanium alloy metal sheet. IOP Conf Ser Mater Sci Eng 430:012015. https://doi.org/10.1088/ 1757-899X/430/1/012015

30. Mori K, Bariani PF, Behrens BA, Brosius A, Bruschi S, Maeno T, Merklein M, Yanagimoto J (2017) Hot stamping of ultra-high strength steel parts. CIRP Ann Manuf Technol 66:755-777. https://doi.org/10.1016/j.cirp.2017.05.007

31. Nakagawa Y, Mori K, Suzuki Y, Shimizu Y (2020) Tailored tempering without die heating in hot stamping of ultra-high strength steel parts. Mater Des 192:108704. https://doi.org/10.1016/j. matdes.2020.108704

32. Yagita R, Abe Y, Munesada Y, Mori K (2020) Deformation behaviour in shearing of ultra-high strength steel sheets under insufficient blankholding force. Procedia Manuf 50:26-31. https://doi.org/10. 1016/j.promfg.2020.08.006

Publisher's note Springer Nature remains neutral with regard to jurisdictional claims in published maps and institutional affiliations. 